\title{
Diabetic foot ulcers: prevention is better than treatment
}

A high proportion of all amputations are performed on patients with diabetes, most commonly because of an infected diabetic foot ulcer. Prevention of foot ulcers in patients with diabetes is extremely important to help reduce the enormous burden of foot ulceration on both patients and health resources [1]. Once diabetic foot ulcers are found, health care providers should attempt to reduce lower extremity amputation risks. Diabetic neuropathy and peripheral arterial disease complicated by infections are major factors involved in a diabetic foot ulcer. Therefore, it is essential to undertake a concomitant management of ischemia, infection, and adequate offloading [2]. Primary health care providers must undertake a careful comprehensive assessment of the feet of the patients with diabetes, evidence of neuropathy, assessment of peripheral arterial disease, and their overall medical conditions.

A multidisciplinary team is required to provide an optimal care for patients with diabetic foot ulcers [3]. The value of glycemic control, wound debridement, advanced wound dressings, offloading foot pressures (e.g., therapeutic shoes or insoles), and surgery to treat chronic ulcer and prevent recurrence should be considered as essential components of management based on the situations of individual diabetic patients. Appropriate education to encourage patients to practice regular foot care to prevent diabetic foot ulcer and its complications cannot be overemphasized. When appropriate, front-line providers should be prepared to adopt a timely referral to specialist care to avoid amputation.

Specialist care for diabetic foot ulcer to avoid amputation includes surgical debridement, wound dressing, treatment of infection, and revascularization. Both general and vascular surgeons may be needed for these procedures. If there is osteomyelitis, orthopedic specialists are essential because all necrotic tissues or infected bones should be removed to reduce recurrent infections. The characteristics of ulcer and postsurgical wound can be important to determine the kind of wound dressings to be selected [4]. For patients who present with a diabetic foot ulcer and severe limb ischemia, early revascularization may be very important [5]. Revascularization may also be considered in patients with a nonhealing ulcer and any degree of limb ischemia [5]. Patients with healed ulcers remain at a high risk for reulceration and need frequent follow up for to maximize ulcer-free, hospital-free, and activity-rich days.

In recent decades, investigators have recognized the potential of mesenchymal stem cells to become a method for treatment of diabetic foot ulcer. Mesenchymal stem cell transplantation may improve wound closure and improve clinical parameters, which might otherwise result in amputation [6]. Bone marrow-derived mesenchymal stem cells have been proposed as a cost-effective transplantation method to treat diabetic foot ulcers and avoid amputation [6]. Adipose-derived stem cells also have potential for the treatment of chronic diabetic wounds [7-9].

In the present issue, Shaflee et al. [10] have offered a narrative review of the present status of stem cell therapy for diabetic foot ulcers. They conclude that there exist various sources of stem cells to enhance angiogenesis in patients with diabetic foot ulcer. The main impediments for successful treatment are the acquisition of a sufficient quality and quantity of stem cells and the inability of these cells to impact the vasculature sufficiently, which is critical for wound healing [10]. According to their review, some stem cells may have teratogenic potential and other side effects [10].

We still do not have good evidence from large randomized controlled trials to convincingly document the effectiveness of stem cell therapy for diabetic foot ulcers [11]. Therefore, it is of paramount importance that patients be encouraged to manage their diabetes mellitus well to avoid diabetic foot ulcers [1],

*Correspondence to: Editorial Office of Asian Biomedicine, Faculty of Medicine, Chulalongkorn University, Bangkok 10330, Thailand, e-mail: abmjournal@chula.ac.th

כ Open Access. ๑ 2021 Editorial Office of Asian Biomedicine, published by Sciendo. (๔) BY-NC-ND This work is licensed under the Creative Commons Attribution NonCommercial-NoDerivatives 4.0 License. 


\section{Allli ASIAN BIOMEDICINE}

which can compromise their quality of life. Prevention of diabetic foot ulcer in patients with diabetes mellitus remains extremely important to help reduce the enormous burden of foot ulceration on both patients and health resources.

\section{References}

[1] van Netten JJ, Price PE, Lavery LA, Monteiro-Soares M, Rasmussen A, Jubiz Y, Bus SA. Prevention of foot ulcers in the at-risk patient with diabetes: a systematic review. Diabetes Metab Res Rev. 2020; 36(Suppl 1):e3270. doi: 10.1002/dmrr.3270

[2] Andrews KL, Houdek MT, Kiemele LJ. Wound management of chronic diabetic foot ulcers: from the basics to regenerative medicine. Prosthet Orthot Int. 2015; 39:29-39.

[3] Yazdanpanah L, Nasiri M, Adarvishi S. Literature review on the management of diabetic foot ulcer. World J Diabetes. 2015; 6:37-53.

[4] Patry J, Blanchette V. Enzymatic debridement with collagenase in wounds and ulcers: a systematic review and meta-analysis. Int Wound J. 2017; 14:1055-65.

[5] Marco M, Valentina I, Daniele M, Valerio DR, Andrea P, Roberto G, et al. Peripheral arterial disease in persons with diabetic foot ulceration: a current comprehensive overview. Curr Diabetes Rev. 2020; 16:1. doi: 10.2174/1573399816999201001203111

[6] Cao Y, Gang X, Sun C, Wang G. Mesenchymal stem cells improve healing of diabetic foot ulcer. J Diabetes Res. 2017; 2017:9328347. doi: 10.1155/2017/9328347

[7] Gadelkarim M, Abushouk AI, Ghanem E, Hamaad AM, Saad AM, Abdel-Daim MM. Adipose-derived stem cells: effectiveness and advances in delivery in diabetic wound healing. Biomed Pharmacother. 2018; 107:625-33. doi: 10.1016/j.biopha.2018.08.013

[8] Moon K-C, Suh H-S, Kim K-B, Han S-K, Young K-W, Lee J-W, Kim M-H. Potential of allogeneic adipose-derived stem cell-hydrogel complex for treating diabetic foot ulcers. Diabetes. 2019; 68:837-46.

[9] Álvaro-Afonso FJ, Sanz-Corbalán I, Lázaro-Martínez JL, Kakagia D, Papanas N. Adipose-derived mesenchymal stem cells in the treatment of diabetic foot ulcers: a review of preclinical and clinical studies. Angiology. 2020; 71:853-63.

[10] Shafiee S, Heidarpour M, Sabbagh S, Amini E, Saffari H, Dolati S, Meamar R. Stem cell transplantation therapy for diabetic foot ulcer: a narrative review. Asian Biomed (Res Rev News). 2021; 15:3-18.

[11] Guo J, Dardik A, Fang K, Huang R, Gu Y. Meta-analysis on the treatment of diabetic foot ulcers with autologous stem cells. Stem Cell Res Ther. 2017; 8:228. doi: 10.1186/s13287-017-0683-2 